\title{
BMJ Open Measuring diabetes guideline adherence with claims data: systematic construction of indicators and related challenges
}

\author{
Agne Ulyte, ${ }^{\oplus 1}$ Caroline Bähler, ${ }^{2}$ Matthias Schwenkglenks, ${ }^{1}$ Viktor von Wyl, ${ }^{1}$ \\ Oliver Gruebner, ${ }^{1,3}$ Wenjia Wei, ${ }^{1}$ Eva Blozik, ${ }^{2}$ Beat Brüngger, ${ }^{2}$ Holger Dressel ${ }^{1}$
}

To cite: Ulyte A, Bähler C, Schwenkglenks M, et al. Measuring diabetes guideline adherence with claims data: systematic construction of indicators and related challenges. BMJ Open 2019;9:e027138. doi:10.1136/ bmjopen-2018-027138

- Prepublication history and additional material for this paper are available online. To view these files, please visit the journal online (http://dx.doi org/10.1136/bmjopen-2018027138).

The preliminary results of the study have been presented at the Wennberg International Collaborative Spring Policy Meeting 2018 in Zurich, Switzerland, and the Guidelines International Network 2018 conference in Manchester, UK.

Received 8 October 2018 Revised 12 March 2019 Accepted 14 March 2019
Check for updates

(c) Author(s) (or their employer(s)) 2019. Re-use permitted under CC BY-NC. No commercial re-use. See rights and permissions. Published by BMJ.

For numbered affiliations see end of article.

Correspondence to

Agne Ulyte; agne.ulyte@uzh.ch

\section{ABSTRACT}

Objectives Indicators of guideline adherence are frequently used to examine the appropriateness of healthcare services. Only some potential indicators are actually usable for research with routine administrative claims data, potentially leading to a biased selection of research questions. This study aimed at developing a systematic approach to extract potential indicators from clinical practice guidelines (CPG), evaluate their feasibility for research with claims data and assess how the extracted set reflected different types of healthcare services. Diabetes mellitus (DM), Swiss national guidelines and health insurance claims data were analysed as a model case.

Methods CPG for diabetes patients were retrieved from the Swiss Endocrinology and Diabetes Society website. Recommendation statements involving a specific healthcare intervention for a defined patient population were translated into indicators of guideline adherence. Indicators were classified according to disease stage and healthcare service type. We assessed for all indicators whether they could be analysed with Swiss mandatory health insurance administrative claims data.

Results A total of 93 indicators were derived from 15 $\mathrm{CPG}$, representing all sectors of diabetes care. For 63 indicators, the target population could not be identified using claims data only. For 67 indicators, the intervention could not be identified. Nine (10\%) of all indicators were feasible for research with claims data (three addressed gestational diabetes and screening, five screening for complications and one glucose measurement). Some types of healthcare services, eg, management of risk factors, treatment of the disease and secondary prevention, lacked corresponding indicators feasible for research.

Conclusions Our systematic approach could identify a number of indicators of healthcare service utilisation, feasible for DM research with Swiss claims data. Some areas of healthcare were covered less well. The approach could be applied to other diseases and countries, helping to identify the potential bias in the selection of indicators and optimise research.

\section{INTRODUCTION}

Health insurance claims data are often used to evaluate the appropriateness and intensity
Strengths and limitations of this study

- This is the first study to explore the limited information from claims data as a source of potential bias when selecting indicators for guideline adherence research.

- A systematic approach was used to develop a comprehensive set of adherence indicators from guidelines, that were then tested for feasibility with claims data.

- Only one clinical area (diabetes mellitus) in a specific country (Switzerland) was investigated as a model case, but the approach could be transferred to other areas of interest.

of healthcare service utilisation in a country, region or hospital. ${ }^{12}$ The Dartmouth Atlas of Health Care in the USA ${ }^{3}$ is an example of such a healthcare service utilisation intensity map. Recently, a similar project, 'Versorgungsatlas', was launched in Switzerland. ${ }^{4}$ Healthcare service appropriateness may additionally be assessed with reference to the clinical indication for the service of interest. In this case, both the patient population with a clinical indication and the corresponding service need to be identifiable. Claims data are used for this purpose in a variety of clinical areas as a valid substitute for clinical data. ${ }^{5-8}$ The resulting indicators, proportions of patients receiving the indicated healthcare services, can be regarded as clinical process quality indicators. ${ }^{9}$ They can be used for research as well as policy development-for example, to assess regional access to services or implementation of clinical practice guidelines (CPG).

The indicators are commonly extracted from CPG or Choosing Wisely lists. ${ }^{11}{ }^{11}$ Indicators of healthcare services overuse have been explored particularly frequently. ${ }^{12-14}$ However, the selection and development of the indicators are often non-systematic. ${ }^{15}$ 


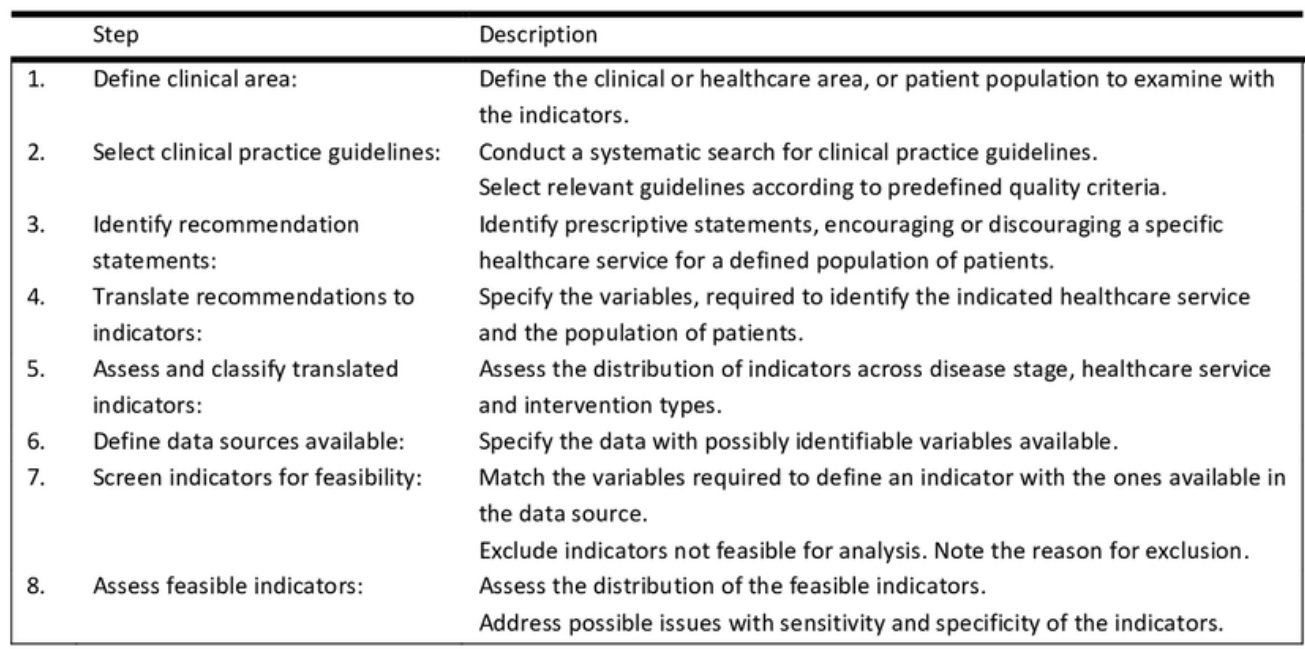

Figure 1 Systematic approach for identifying indicators of guideline adherence for research with claims data.

Even when based on CPG and guided by clinical relevance, the selection of the analysed indicators is at the discretion of the researchers and may be strongly influenced by the availability of data. ${ }^{10}$ Feasibility is frequently used as a criterion to select healthcare quality indicators. ${ }^{16}$ As a result, there may be a danger that some healthcare services research and monitoring could be driven by opportunities and data available rather than by a systematic assessment of relevant research questions from a patient or societal perspective.

Specifically, potential bias in indicator selection may arise as claims data typically do not cover all aspects of healthcare. In fee-for-service and bundled payment healthcare reimbursement systems, clinical information is normally not recorded with the reimbursement claim. ${ }^{17}$ For example, in Swiss claims databases, outpatient diagnoses and indications are not recorded with the provided outpatient services. ${ }^{18}$ With limited clinical information, some patient populations may not be accurately identifiable, and consequently, appropriateness of healthcare service utilisation in these populations may not be assessed. This could lead to a bias of disproportionate application of more easily assessable indicators.

Systematic development and application of indicators of guideline adherence may reduce the possibility of imbalanced selection of topics in healthcare service utilisation research. A few recent studies have systematically extracted indicators of low-value care and evaluated their feasibility for research in primary care ${ }^{19}$ or inpatient settings. ${ }^{11}$ In contrast to extracting only the feasible indicators, the aim of this study was to additionally quantify the indicators unavailable and healthcare services not reflected due to limitations of claims data. Our study aimed to develop a comprehensive, systematic approach to extract and assess guideline adherence indicators for a case model of diabetes mellitus (DM) in Switzerland. CPG were used to systematically develop indicators and mandatory health insurance data to test their feasibility for research. DM is an example of a highly prevalent chronic disease that has a comprehensive national guideline set in Switzerland, published by the Swiss Society for Endocrinology and Diabetes (Schweizerischen Gesellschaft für Endokrinologie und Diabetologie). ${ }^{20}$ Research on specific DM services indicators based on claims data has already been shown to be feasible. ${ }^{21}{ }^{22}$ However, the scope of all feasible indicators has not been assessed systematically in diabetes or any other single clinical area across all healthcare settings.

\section{METHODS}

\section{Systematic development of guideline adherence indicators}

In the first step, we designed a systematic approach for the development of guideline adherence indicators for a specific patient population or clinical area. As we have found no previous published detailed approach, we designed the algorithm based on the agreement of all study authors. The final approach is illustrated in figure 1 .

Second, we applied this approach to DM and Swiss administrative claims data. We retrieved all current guideline and recommendation documents published online on the official website of the Swiss Endocrinology and Diabetes Society in German. ${ }^{20}$ From the documents retrieved, DM-CPG were identified, resulting in 15 unique documents.

An indicator of guideline adherence was defined as the ratio of patients who actually receive a healthcare service, to all patients with an indication for that specific service. Therefore, to translate a recommendation statement to an indicator, both the patient population with the indication for a service and the patients receiving the service need to be defined. We selected recommendation statements that had both the indication (population) and healthcare service defined. Exclusion criteria for recommendation statements were as follows:

1. The recommendation does not result in any intervention directly affecting the individual patient (eg, a certain risk stratification tool recommended for a specific 
patient population; documentation of healthcare service delivery).

2. The recommendation expresses no preference for a specific service, in the presence of multiple options (eg, initial therapy for DM patients with symptomatic hyperglycaemia or metabolic decompensation should be started with insulin with or without metformin).

3 . The recommendation is a non-specific principle (eg, pharmaceutical therapy should be started without unnecessary delay).

4. No recommendation signalling words (such as should ['soll', 'sollte'], must ['muss'], we recommend ['wir empfehlen'], is not recommended ['ist nicht empfohlen'] and so on) are used in the recommendation (eg, general statements of common current practice).

In order to maintain a comprehensive approach, we did not further exclude recommendation statements based on the nature of the recommended intervention (eg, interventions of general vs specialised practice, positive vs negative recommendations, recommendations for diabetes management vs comorbidities management in diabetic patients).

Eligible recommendation statements were then translated into indicators of guideline adherence. We classified the indicators according to: (1) disease stage (screening-general population; risk factor-patients with an established risk factor for diabetes; diseasepatients with diabetes), (2) area of healthcare service (screening-testing of population without symptoms; diagnosis-interventions to confirm or reject the diagnosis; primary prevention-interventions to prevent the onset of disease; control-routine interventions for a patient with a disease; treatment-therapeutic measures; secondary prevention-interventions to prevent disease progression) and (3) intervention type (clinical test-a specific non-laboratory examination, such as blood pressure measurement, medical history taking or a questionnaire administration; laboratory test-blood or urine laboratory analysis; consultation-a consultation of a specialist, such as ophthalmologist, a teaching session or a specific medical advice given during a physician consultation; medication-direct pharmacological intervention; device use-prescription of a medical device, such as for continuous glucose measurement). This classification broadly covers all types, functions and modalities of healthcare services. ${ }^{9}$

\section{Screening indicators for feasibility}

As a next step, information from administrative mandatory health insurance claims data was identified and characterised in cooperation with the research team of a major healthcare insurance provider in Switzerland (BB, CB, EB). The claims database consists of information on reimbursed healthcare diagnostic and therapeutic services, deemed appropriate clinically and cost-effective, from all healthcare service providers settings. The information is coded according to international or national classification or tariff systems. Major types of patient information
Table 1 Major categories of patient data available in Swiss mandatory health insurance claims databases

\begin{tabular}{lll}
\hline Data category & Inpatient data & $\begin{array}{l}\text { Outpatient } \\
\text { data }\end{array}$ \\
\hline Diagnosis & $\begin{array}{l}\text { SwissDRG, ICD- } \\
10-G M\end{array}$ & - \\
\hline Procedures & SwissDRG, CHOP & Tarmed \\
Laboratory tests & - & Analysenliste \\
\hline Medication & - & ATC \\
Materials and devices & - & MiGeL \\
Summary of services & SwissDRG & - \\
\hline
\end{tabular}

Abbreviations of data sources: SwissDRG (Swiss DiagnosisRelated Groups, a classification of inpatient cases, based on diagnoses, procedures and other clinical information), CHOP (Schweizerische Operationsklassifikation, a classification of inpatient procedures), ICD-10-GM (International Classification of Diseases, 10th revision, German Modification, codes for primary and secondary diagnoses for each hospitalisation episode of an inpatient), Tarmed (classification of outpatient procedures and services), Analysenliste (outpatient laboratory test codes), ATC (Anatomical Therapeutic Chemical Classification System, code and quantity of a prescription drug), MiGeL (Mittel und Gegenständeliste, classification of therapeutic materials and devices).

References for the listed data sources are provided in online supplementary file 1 .

available in the claims database and the corresponding coding systems used are given in table 1 . In addition, demographic data, such as sex and age, are available.

Next, it was checked if both the addressed population and intervention of the indicator could be identified in the claims data. Indicators were excluded as not feasible if either the patient population or intervention could not be identified. The reason for exclusion was noted. These steps were performed by two authors in duplicate (AU and $\mathrm{CB}$ ), and instances of disagreement resolved by discussion with the other authors.

For example, one of the identified CPG in Switzerland, Criteria for Good Disease Management of Diabetes in Primary Care (Kriterien für ein „gutes "Disease Management Diabetes in der Grundversorgung), recommends that 'to fulfil the score criteria, glycated haemoglobin $\left(\mathrm{HbA}_{1 c}\right)$ should be measured at least two times per year (for diabetes patients)". The recommendation identifies both the population (diabetes patients) and the intervention ( $\mathrm{HbA}_{1 c}$ at least biannually), therefore the translated indicator is the fraction of all diabetes patients who get the test done at least biannually. According to our classification, this is an indicator of a laboratory control test performed routinely for diabetes patients. Eligibility of the indicator can now be checked, and the required variables identified in the claims database (to define the population: data on the prescription of diabetes medication; to define the intervention: $\mathrm{HbA}_{1 \mathrm{c}}$ outpatient test performance). 


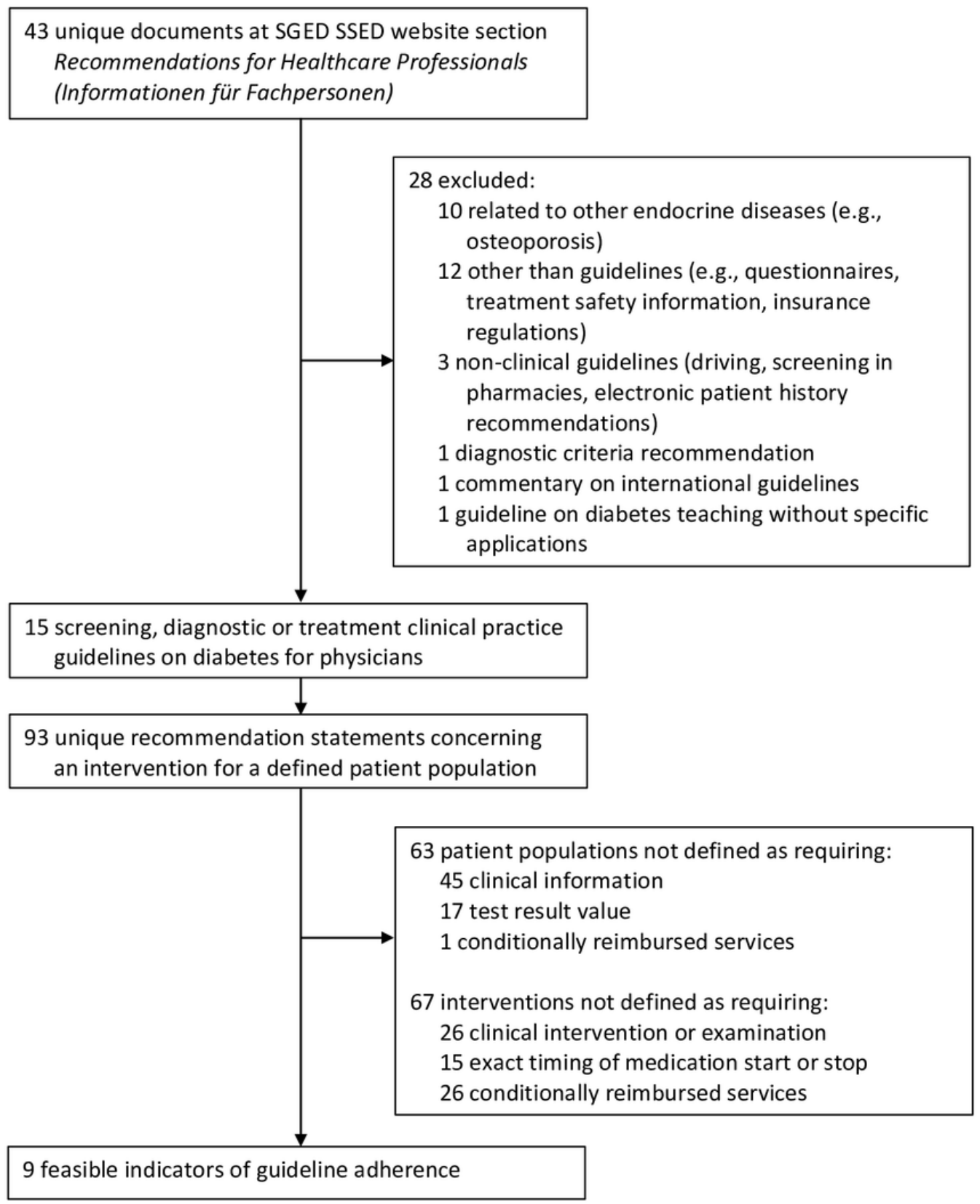

Figure 2 Selection of clinical practice guidelines, recommendation statements and indicators of guideline adherence.

\section{Patient and public involvement}

This study was performed as part of the National Research Programme 74 'Smarter Health Care' of the Swiss National Science Foundation. Patients and public, including policy makers and healthcare services providers, are involved in interpreting, disseminating and translating the overall results of studies conducted under this programme. Patients were not directly involved in the planning and conducting of this study.

\section{RESULTS}

From 15 CPG on DM, 93 explicit recommendation statements were translated into indicators (figure 2). Nine $(10 \%)$ of these indicators could be identified from the administrative claims data available (ie, both the population and the indicated intervention could be identified) and would be principally feasible for further analysis (table 2). Specific codes to identify the patient population and the intervention for each feasible indicator from the claims data sources are provided in online supplementary file 2.

For 63 indicators, the patient population could not be identified, and for 67 indicators, the intervention could not be identified with sufficient accuracy (figure 2). Missing clinical information (eg, clinical examination details) prevented the identification of 45 populations and 26 interventions. Missing test results (eg, HbAlc test value) resulted in a failure to identify another 17 
Table 2 Feasible indicators based on diabetes recommendation statements

\begin{tabular}{|c|c|c|c|c|c|}
\hline $\begin{array}{l}\text { Reference clinical practice } \\
\text { guideline }\end{array}$ & & Population & $\begin{array}{l}\text { Data } \\
\text { source }\end{array}$ & Intervention & $\begin{array}{l}\text { Data } \\
\text { source }\end{array}$ \\
\hline \multirow{2}{*}{$\begin{array}{l}\text { Primary Health Care Good } \\
\text { Disease Management } \\
\text { Criteria* }\end{array}$} & 1 & DM patients & ATC & HbA1c test twice yearly & Ana \\
\hline & 3 & DM patients & ATC & $\begin{array}{l}\text { Serum creatinine and } \\
\text { microalbuminuria tests annually }\end{array}$ & Ana \\
\hline $\begin{array}{l}\text { Gestational Diabetes } \\
\text { Screening } †\end{array}$ & $5 / 6 \neq$ & $\begin{array}{l}\text { Pregnant women in } \\
24-28 \text { weeks / in the third } \\
\text { trimester of pregnancy, if } \\
\text { not screened earlier }\end{array}$ & DRG, Ana & $\begin{array}{l}\text { Oral glucose tolerance test } \\
\text { (OGTT) or fasting glucose test }\end{array}$ & Ana \\
\hline $\begin{array}{l}\text { Blood Glucose Self- } \\
\text { Monitoring }\end{array}$ & 9 & $\begin{array}{l}\text { DM patients on intensive } \\
\text { insulin therapy }\end{array}$ & ATC & $\begin{array}{l}7-8 \text { blood glucose } \\
\text { measurements daily }\end{array}$ & MiGeL \\
\hline
\end{tabular}

URL links to the referenced guidelines are provided in online supplementary file 3.

*DE: Kriterien für ein 'gutes' Disease Management Diabetes in der Grundversorgung.

†DE: Screening des Gestationsdiabetes.

$\ddagger$ Two recommendation statements are combined for this indicator.

$\S D E$ : Empfehlungen bezüglich der Insulintherapie bei unselbständigen Patienten;

IDE: Selbst-Monitoring der Blutglukose.

Ana, Analyseliste (outpatient laboratory test codes); ATC, Anatomical Therapeutic Chemical Classification System; DM, diabetes mellitus; DRG, diagnosis-related group; HbA1c, glycated haemoglobin; ICD, International Statistical Classification of Diseases and Related Health Problems, 10th revision; MiGeL, Mittel und Gegenständeliste (classification of therapeutic materials and devices); TM, TARMED Tarif (classification of outpatient procedures and services).

populations. In other cases, populations and interventions could not be identified due to unavailable initial date of a diagnosis or a prescription, information on the utilisation frequency of diagnostic tests or devices (except when monthly utilisation rate could be used as a proxy for daily utilisation), and limited information on the use of some devices.

Of the indicators suitable for analysis with claims data, three addressed gestational diabetes and DM screening, five addressed routine screening for DM complications and one the mode of blood glucose measurement (table 2). Indicators suitable for analysis were distributed unequally across disease stages, areas of healthcare services and interventions (table 3). For some areas of healthcare services, no feasible indicators were available. Examples include interventions to diagnose and treat risk factors, medication and device use for disease treatment, and secondary prevention of complications.

\section{DISCUSSION}

We developed a systematic approach and identified potential indicators of guideline adherence that can be used for research with Swiss health insurance claims data, using DM as a case model. Only a fraction of indicators generated from CPG recommendation statements was feasible for research, distributed unequally across different healthcare services types and areas.

Claims databases are a frequent source of data for research on healthcare utilisation, ${ }^{1}$ increasingly used in Switzerland. ${ }^{18} 21$ 23-26 Limitations of the claims data could lead to some of the potential indicators being over- or under-represented in research with this data source. Ultimately, such a selective set of indicators, when used to link healthcare funding to provider performance, could potentially distort the way healthcare is provided. In our study, no identified indicator was feasible to assess medication or continuous glucose monitoring device use, even though these service categories comprised the largest number of potential indicators (table 3 ). In contrast, all four identified indicators of control laboratory testing were feasible for research. Such imbalanced distribution confirms a risk of bias, if the indicator selection is guided by the available data rather than the clinical or public health relevance.

Despite potential shortcomings, research on healthcare service utilisation with claims data is attractive as they provide real-life, up-to-date information and may be a valid substitute for clinical data in some cases. ${ }^{5}$ They 


\begin{tabular}{|c|c|c|c|c|}
\hline $\begin{array}{l}\text { Disease } \\
\text { stage }\end{array}$ & $\begin{array}{l}\text { Area of } \\
\text { healthcare } \\
\text { service }\end{array}$ & $\begin{array}{l}\text { Intervention } \\
\text { type }\end{array}$ & $\begin{array}{l}\text { No. of } \\
\text { indicators }\end{array}$ & $\begin{array}{l}\text { No. of } \\
\text { feasible } \\
\text { indicators }\end{array}$ \\
\hline & & & 93 & $9(10 \%)$ \\
\hline \multirow[t]{2}{*}{ Screening } & \multirow[t]{2}{*}{ Screening } & Clinical test & 1 & 0 \\
\hline & & $\begin{array}{l}\text { Laboratory } \\
\text { test }\end{array}$ & 2 & 2 \\
\hline \multirow[t]{3}{*}{ Risk factor } & Screening & $\begin{array}{l}\text { Laboratory } \\
\text { test }\end{array}$ & 1 & 0 \\
\hline & Diagnosis & $\begin{array}{l}\text { Laboratory } \\
\text { test }\end{array}$ & 4 & 0 \\
\hline & $\begin{array}{l}\text { Primary } \\
\text { prevention }\end{array}$ & Consultation & 1 & 0 \\
\hline \multirow[t]{13}{*}{ Disease } & Screening & Clinical test & 1 & 0 \\
\hline & \multirow[t]{2}{*}{ Diagnosis } & $\begin{array}{l}\text { Laboratory } \\
\text { test }\end{array}$ & 1 & 1 \\
\hline & & Device use & 1 & 0 \\
\hline & \multirow[t]{3}{*}{ Control } & Consultation & 3 & 1 \\
\hline & & Clinical test & 4 & 0 \\
\hline & & $\begin{array}{l}\text { Laboratory } \\
\text { test }\end{array}$ & 4 & 4 \\
\hline & \multirow[t]{5}{*}{ Treatment } & Clinical test & 3 & 0 \\
\hline & & $\begin{array}{l}\text { Laboratory } \\
\text { test }\end{array}$ & 12 & 1 \\
\hline & & Consultation & 6 & 0 \\
\hline & & Medication & 19 & 0 \\
\hline & & Device use & 25 & 0 \\
\hline & \multirow{2}{*}{$\begin{array}{l}\text { Secondary } \\
\text { prevention }\end{array}$} & Consultation & 3 & 0 \\
\hline & & Medication & 2 & 0 \\
\hline
\end{tabular}

The categories used for the classification of disease stages, areas of healthcare services and intervention types are explained in the methods section.

are gathered from all settings and providers and are recorded in standard variables (table 1). Therefore, they are easily comparable across patients and providers and can be used to construct country-wide healthcare utilisation intensity maps. ${ }^{34}$ Longitudinal data can be linked directly to the patient, as implemented in Sweden, ${ }^{27}$ leading to a unified national database. In Switzerland, the clinical details are currently stored locally by the service provider, and the administrative information is linked to the patient through the insurer, with a strategy to implement a unified eHealth record database in a few years. ${ }^{28}$

The number of feasible indicators could be increased by allowing more uncertainty in the population or intervention definitions. For example, DM type is not recorded in the claims database. However, it could be estimated from patient characteristics and prescription patterns. ${ }^{29}$ Indicators requiring knowledge of DM type could be considered on this basis. Further sensitivity analyses for patients hospitalised in the years of interest could be based on inpatient diagnoses, which are recorded in the claims data. However, complex identification algorithms might decrease the sensitivity or specificity of the indicators, and render the retrieval and analysis of the data overly complicated.

In addition to reimbursement claims, other data sources could be explored for systematic application of guidelines adherence indicators. Electronic healthcare record data, gathered on a national level, could provide more clinical details. This could extend the spectrum of the feasible indicators, as major reasons for indicator exclusion in this study were missing clinical examination and laboratory test results. However, health records might face other problems-such as different interpretation across providers, missing data and various quality issues. Another alternative data source is disease registries, providing focused information on guideline adherence in specific diseases, such as myocardial infarction. ${ }^{30}$

Although the general approach developed in our study is broadly applicable, the model case of diabetes care in Switzerland is limited to the specificities of the national claims data structure and the peculiarities of the analysed disease. Data collected in claims databases vary by country, ${ }^{131}$ limiting the possibility to apply the developed indicators internationally. Most of the reported indicators of healthcare service utilisation have been developed in the USA, ${ }^{12}$ where unlike in Switzerland outpatient diagnoses in Medicare claims data may be available. ${ }^{32} \mathrm{DM}$ patients in Swiss claims data could be identified by drug prescription; however, DM controlled by diet only would be missed. ${ }^{33}$ Some of the indicators developed in this study would rely on indirect identification, for example, the stage of pregnancy would have to be estimated from the date of delivery. All indicators, especially relying on indirect identification algorithms, should ideally be assessed with sensitivity analysis and validated. Algorithms to identify specific patient populations with claims data are frequently validated; however, validation is rarely applied to indicators of utilisation. ${ }^{345}$

DM is an example of a disease for which the medications prescribed are specific enough to suffice for patient identification. Only a limited range of other diseases can be identified in a similarly clear-cut way (eg, hypothyroidism, osteoporosis or tuberculosis). For many frequently prescribed drugs, the indications are wide and overlapping, precluding identification of a specific disease or at least rendering it more uncertain. ${ }^{36}$ This limits the transferability of our approach to some diseases, although algorithms also considering non-drug outpatient services can provide solutions in some cases (eg, combining a prescription of a drug at a specific dosage by a certain specialty physician). We ensured a systematic approach by pre-specifying the inclusion and exclusion criteria for indicators, and with a concurrent assessment by two authors. However, a further limitation is related to the structure of the CPG used for indicator extraction. Inaccuracies may have arisen due to inherent uncertainties in the formulations of the recommendation statements in 
these CPG. Recommendation statements were usually not specifically highlighted in the analysed CPG texts and did not have standard formatting or wording, which could lead to a slightly different interpretation by different reviewers. The strength of recommendations or the level of evidence were rarely stated in the analysed guidelines, which would have been useful criteria to classify the indicators. One of the reasons for these shortcomings is that CPG are not specifically designed for indicator construction (just as claims databases are not designed for their assessment). These shortcomings could be minimised by analysing guidelines with clearly structured recommendation statements, such as in the Consensus Report by the American Diabetes Association and the European Association for the Study of Diabetes. ${ }^{37}$

Some of the feasible DM indicators identified in this study have already been demonstrated to be fruitful for research. Huber $e t a l^{21}$ used medication prescriptions to identify a population of drug-treated diabetes patients from the claims database. The investigated interventions were the frequency of $\mathrm{HbA}_{1 c}$, lipid profile and nephropathy status testing and ophthalmologist visits. These indicators were identified as feasible in this study as well.

\section{CONCLUSIONS}

Using the systematic approach, a number of indicators could be identified for research on diabetes healthcare service utilisation with claims data. Not all healthcare services were represented equally. We believe that our approach could be applied to other diseases and databases in other countries, helping to identify the potential bias in the selection of indicators and optimise such research. In parallel, the structure and content of claims databases may be optimised to allow more efficient healthcare services research in the future. More clearly, structured guidelines with evident recommendation statements would also facilitate their extraction. Comparing the validity of indicators constructed for different national databases could further inform policymakers regarding the advantages of different data collection strategies.

\section{Author affiliations}

${ }^{1}$ Epidemiology, Biostatistics and Prevention Institute (EBPI), University of Zurich, Zurich, Switzerland

${ }^{2}$ Department of Health Sciences, Helsana Group, Zurich, Switzerland

${ }^{3}$ Geography Department, University of Zurich, Zurich, Switzerland

Contributors $\mathrm{AU}$ and $\mathrm{HD}$ designed the study, with contributions from MS, VvW, $\mathrm{OG}, \mathrm{WW}, \mathrm{EB}, \mathrm{BB}$ and $\mathrm{CB}$. AU collected the relevant guidelines. $\mathrm{CB}, \mathrm{EB}$ and $\mathrm{BB}$ detailed the claims data sources. $A U$ and $C B$ screened the guidelines and resultant indicators. $\mathrm{AU}$ and $\mathrm{HD}$ conducted the analysis. All authors contributed to interpreting the results. $\mathrm{AU}$ was the primary contributor in writing the manuscript, with major contributions from MS, VvW, OG and HD. All authors read and approved the final manuscript.

Funding This work was supported by the SNSF National Research Programme 'Smarter Health Care' (NRP 74), project number 26, grant number 407440_167349.

Competing interests None declared.

Patient consent for publication Not required.

Provenance and peer review Not commissioned; externally peer reviewed.
Data sharing statement No unpublished data are currently available outside the study team. Additional information and links to the analysed guidelines are available in the Supplementary material.

Open access This is an open access article distributed in accordance with the Creative Commons Attribution Non Commercial (CC BY-NC 4.0) license, which permits others to distribute, remix, adapt, build upon this work non-commercially, and license their derivative works on different terms, provided the original work is properly cited, appropriate credit is given, any changes made indicated, and the use is non-commercial. See: http://creativecommons.org/licenses/by-nc/4.0/.

\section{REFERENCES}

1. Kreis K, Neubauer S, Klora M, et al. Status and perspectives of claims data analyses in Germany-a systematic review. Health Policy 2016;120:213-26.

2. Ferver K, Burton B, Jesilow P. The use of claims data in healthcare research. Open Public Health J 2009;2:11-24.

3. The Trustees of Dartmouth College. Dartmouth atlas of health care. http://www.dartmouthatlas.org/ (accessed 5 Feb 2018).

4. Berlin C, Spörri A, Staub LP, et al. Regionale Variabilität von stationären Behandlungen in der Schweiz. Schweizerische Ärztezeitung 2018;99:40-4.

5. Behrendt CA, Heidemann F, Rieß HC, et al. Registry and health insurance claims data in vascular research and quality improvement. Vasa 2017;46:1-5.

6. Stein JD, Lum F, Lee PP, et al. Use of health care claims data to study patients with ophthalmologic conditions. Ophthalmology 2014;121:1134-41.

7. Pugely AJ, Martin CT, Harwood J, et al. Database and registry research in orthopaedic surgery. J Bone Joint Surg 2015;97:1278-87.

8. Yu AY, Holodinsky JK, Zerna C, et al. Use and utility of administrative health data for stroke research and surveillance. Stroke 2016;47:1946-52.

9. Mainz J. Defining and classifying clinical indicators for quality improvement. Int J Qual Health Care 2003;15:523-30.

10. Campbell SM, et al. Improving the quality of health care: research methods used in developing and applying quality indicators in primary care. BMJ 2003;326:816-9.

11. Chalmers K, Badgery-Parker T, Pearson SA, et al. Developing indicators for measuring low-value care: mapping Choosing Wisely recommendations to hospital data. BMC Res Notes 2018;11:163.

12. Segal JB, Bridges JF, Chang HY, et al. Identifying possible indicators of systematic overuse of health care procedures with claims data. Med Care 2014;52:157-63.

13. Elshaug AG, Watt AM, Mundy L, et al. Over 150 potentially lowvalue health care practices: an Australian study. Med J Aust 2012;197:556-60.

14. de Vries EF, Struijs JN, Heijink R, et al. Are low-value care measures up to the task? A systematic review of the literature. BMC Health Serv Res 2016;16:405.

15. Korenstein $D$, et al. Overuse of health care services in the United States. Arch Intern Med 2012;172:171.

16. Boulkedid R, Abdoul H, Loustau M, et al. Using and reporting the Delphi method for selecting healthcare quality indicators: a systematic review. PLoS One 2011;6:e20476.

17. Mazzali C, Duca P. Use of administrative data in healthcare research. Intern Emerg Med 2015;10:517-24.

18. Bähler C, Vavricka SR, Schoepfer AM, et al. Trends in prevalence, mortality, health care utilization and health care costs of Swiss IBD patients: a claims data based study of the years 2010, 2012 and 2014. BMC Gastroenterol 2017;17:138.

19. Sprenger M, Robausch M, Moser A. Quantifying low-value services by using routine data from Austrian primary care. Eur J Public Health 2016;26:912-6.

20. Swiss Endocrinology and Diabetes Society. Recommendations for professionals. http://sgedssed.ch/informationen-fuer-fachpersonen/ (accessed 7 Nov 2017).

21. Huber CA, Brändle M, Rapold R, et al. A set of four simple performance measures reflecting adherence to guidelines predicts hospitalization: a claims-based cohort study of patients with diabetes. Patient Prefer Adherence 2016;10:223-31.

22. Shah BR, Hux JE, Laupacis A, et al. Administrative data algorithms can describe ambulatory physician utilization. Health Serv Res 2007;42:1783-96.

23. Blozik E, Rapold R, Eichler K, et al. Epidemiology and costs of multiple sclerosis in Switzerland: an analysis of health-care claims data, 2011-2015. Neuropsychiatr Dis Treat 2017;13:2737-45. 
24. Huber CA, Schwenkglenks M, Rapold R, et al. Epidemiology and costs of diabetes mellitus in Switzerland: an analysis of health care claims data, 2006 and 2011. BMC Endocr Disord 2014;14:44.

25. Chmiel C, Reich O, Signorell A, et al. Appropriateness of diagnostic coronary angiography as a measure of cardiac ischemia testing in non-emergency patients - a retrospective cross-sectional analysis. PLoS One 2015;10:e0117172.

26. Blozik E, Reich O, Rapold R, et al. Evidence-based indicators for the measurement of quality of primary care using health insurance claims data in Switzerland: results of a pragmatic consensus process. BMC Health Serv Res 2018;18:743.

27. Ahlm M, Hellström N, Nemie J, et al. National eHealth - the strategy for accessible and secure information in health and social care. 2010 www.sweden.gov.se/ehealth (accessed 7 Feb 2018).

28. De Pietro C, Francetic I. E-health in Switzerland: the laborious adoption of the federal law on electronic health records (EHR) and health information exchange (HIE) networks. Health Policy 2018;122:69-74.

29. Vanderloo SE, Johnson JA, Reimer K, et al. Validation of classification algorithms for childhood diabetes identified from administrative data. Pediatr Diabetes 2012;13:229-34.

30. Müller A, Maggiorini M, Radovanovic D, et al. Twenty-year trends in the characteristic, management and outcome of patients with ST-elevation myocardial infarction and out-of-hospital reanimation.
Insight from the national AMIS PLUS registry 1997-2017. Resuscitation 2019;134:55-61.

31. Moulis G, Lapeyre-Mestre M, Palmaro A, et al. French health insurance databases: What interest for medical research? Rev Med Interne 2015;36:411-7.

32. Erdem E, Korda H, Haffer SC, et al. Medicare Claims Data as Public Use Files. Journal of Public Health Management and Practice 2014;20:445-52.

33. Tu K, Manuel D, Lam K, et al. Diabetics can be identified in an electronic medical record using laboratory tests and prescriptions. $J$ Clin Epidemiol 2011;64:431-5.

34. Moura LM, Price M, Cole AJ, et al. Accuracy of claims-based algorithms for epilepsy research: Revealing the unseen performance of claims-based studies. Epilepsia 2017;58:683-91.

35. Hoffmann F. Review on use of German health insurance medication claims data for epidemiological research. Pharmacoepidemiol Drug Saf 2009;18:349-56.

36. Wong J, Motulsky A, Eguale T, et al. Treatment Indications for Antidepressants Prescribed in Primary Care in Quebec, Canada, 2006-2015. JAMA 2016;315:2230.

37. Davies MJ, D'Alessio DA, Fradkin J, et al. Management of Hyperglycemia in Type 2 Diabetes, 2018. A Consensus Report by the American Diabetes Association (ADA) and the European Association for the Study of Diabetes (EASD). Diabetes Care 2018;41:2669-701. 